Research Article

\title{
Experimental Study on Physical-Mechanical Properties of Expansive Soil Improved by Multiple Admixtures
}

\author{
Binhui Ma ${ }^{10},{ }^{1,2}$ Kai Cai, ${ }^{1}$ Xing Zeng, ${ }^{1}$ Zhuo Li, ${ }^{1}$ Zhiyong Hu, ${ }^{1}$ Qiunan Chen,,2 \\ Chengbin He, ${ }^{1}$ Bingchu Chen, ${ }^{1}$ and Xiaocheng Huang ${ }^{1,2}$ \\ ${ }^{1}$ School of Civil Engineering, Hunan University of Science and Technology, Xiangtan 411201, China \\ ${ }^{2}$ Hunan Provincial Key Laboratory of Geotechnical Engineering for Stability Control and Health Monitoring, \\ Hunan University of Science and Technology, Xiangtan 411201, China
}

Correspondence should be addressed to Binhui Ma; mbh@hnust.edu.cn

Received 20 February 2021; Accepted 7 May 2021; Published 20 May 2021

Academic Editor: Rihong Cao

Copyright (c) 2021 Binhui Ma et al. This is an open access article distributed under the Creative Commons Attribution License, which permits unrestricted use, distribution, and reproduction in any medium, provided the original work is properly cited.

The treatment of expansive soil is always a difficult problem in engineering. Using coal gangue, fly ash, and other solid waste to treat expansive soil has gradually become a new way of energy saving and environmental protection. Most of the existing studies focus on using one or two kinds of admixtures to improve expansive soil, but there are few studies on improving expansive soil with multiple admixtures. In this paper, the expansion and shrinkage deformation and strength characteristics of expansive soil modified by coal gangue, fly ash, and lime are studied experimentally. Nine groups of different mixing schemes were designed through orthogonal tests, and the physical and mechanical properties of the improved expansive soil under different mixing ratios were tested. The sensitivity analysis of the test results was carried out to study the effect of each admixture on the improved expansive soil under different mixing ratios, and the optimal mix ratio under different conditions was obtained. The optimal mix ratio is $8 \%$ for coal gangue, $11 \%$ for fly ash, and $6 \%$ for lime. Further scanning electron microscopy (SEM) tests were carried out to analyze the microstructure of the improved expansive soil and explore the improvement mechanism of the multiadmixture. The results show that the optimal moisture content and the maximum dry density of the expansive soil with ash are decreased, and the properties of liquid plastic limit, free expansion rate, shear strength, and unconfined compressive strength of the expansive soil are improved obviously. Through the analysis of the comprehensive balance method, it is found that the content of lime has the greatest influence on the improvement effect of expansive soil, followed by that of coal gangue, and the least is that of fly ash. SEM structure analysis reveals that the particles of improved expansive soil are mainly aggregates, the soil structure is dense, particle agglomeration increases, and the overall structure is stronger. The research results can provide reference for the improvement of expansive soil with various admixtures and the resource utilization of coal gangue, fly ash, and other solid wastes.

\section{Introduction}

Coal gangue is the carbonaceous rock with high ash content and low calorific value associated with coal and is one of the largest industrial solid wastes in China [1]. In addition, it is easy to cause landslides, disintegration, and spontaneous combustion to produce toxic gases and other hazards, which seriously affect the agricultural ecological environment and people's healthy lives. Expansive soil, as a kind of diseased soil that affects the construction of farmland water conservancy facilities and other projects, has the characteristics of water-absorbing expansion, water-loss shrinkage, waterbearing capacity reduction, and dry shrinkage crack [2-5]. Its properties are extremely unstable, which will lead to cracks, inclinations, and other hazards in road subgrade and construction. In terms of research on gangue and improved expansive soil, Liu et al. [6] studied the addition of gangue to cement, concrete, and other building materials and proposed that gangue can improve various properties of building materials, as well as the types, particle size, dosage, and grading of gangue. Wang and Wang [7] found that the physical and mechanical properties, corrosion resistance, 
carbonation resistance, and reinforcement performance of gangue cement with less clinker, mainly coal gangue, were good through testing and analysis. Meng [8] established the relationship between the ratio of gangue and the parameters of shear strength and the relationship between the California Bearing Ratio (CBR) value and the compacting degree and the ratio of gangue through laboratory tests and analysis and calculation. Shen et al. [9] studied the composite improvement of strong expansive soil with lime, potassium chloride, polyvinyl alcohol, and polypropylene fiber and verified the effectiveness of the improved method by free expansion rate test and shear test. By analyzing gangue content and X-ray diffraction, Yang and Zhang [10] proved that the materials separated from coal gangue could be consolidated with expansive soil or undergo ion exchange reaction to improve the cohesion and shear strength of expansive soil. Zhang et al. $[11,12]$, respectively, studied the changes of various indexes of coal gangue powder and lime + coal gangue to improve expansive soil through laboratory tests of physical and mechanical properties and obtained that coal gangue powder and lime + coal gangue can effectively improve the physical properties of expansive soil and give the optimal mixing ratio of improved expansive soil. Wang [13] studied the expansive soil of the runway of Hefei Xinqiao Airport by combining laboratory experiment and field experiment. By adding lime to improve the expansive soil, good results are obtained, and the actual engineering requirements are satisfied. Qiu [14] studied the characteristics of lime improved expansive soil under dry wet cycle and carried out compaction test, free expansion rate test, crack development test, and consolidation fast shear test. According to the field construction and economy, it is suggested that the lime content should be 5\%. Dai [15] used energy dispersive analysis of x-rays (EDAX) to analyze the composition of expansive soil and modified expansive soil with lime and concluded that the modification effect of lime modified expansive soil was better than that of fly ash modified expansive soil. Abbaspour et al. [16] modified the expansive soil with the Waste Tire Textile Fibers (WTTFs). The mechanical properties of sodium bentonite containing WTTF were evaluated by a set of standard compactions, direct shear, unconfined compressive strength (UCS), CBR, and expansive consolidation tests. Indiramma et al. [17] conducted an experimental investigation to study the individual and combined effects of admixtures viz, lime, and fly ash on the geotechnical characteristics of expansive soil. It is concluded that the combination of lime or fly ash and lime can be used as an effective stabilizing additive for expansive soil. Gireesh Kumar and Harika [18] used fly ash and other wastes as admixtures, mixed with expansive soil as stabilizer of expansive soil, for testing (to form a uniform and stable road base). The results show that more than $10 \%$ fly ash and black cotton soil are recommended to be used as the mixture, which can be used in the construction of paving stones and other foundation projects.

The above studies mostly improve the expansive soil subgrade from single admixture or double admixture, while the improvement of expansive soil with multiple admixtures remains to be further explored. In view of the existence and harm of large amount of gangue waste, and the adverse effect of expansion and shrinkage of expansive soil on engineering construction, this paper analyzes and studies the feasibility and effect of the improvement of expansive soil in southern Hunan province with the addition of gangue, fly ash, and lime. With coal gangue, fly ash, and lime as test factors, the dosage of level, using the orthogonal design, 9 sets of test plan formulation, indoor routine test, and SEM test, and through the data analysis of expansive soil under different mixing ratio of various factors and the influence law of physical and mechanical properties and microstructure, determine its improvement effect, and the new improved expansive soil formula is concluded, which will provide a scientific basis for improved expansive soil engineering disease problem and engineering reference.

\section{Experiments}

2.1. Raw Material. Raw materials include expansive soil, coal gangue, fly ash, and lime. The expansive soil, coal gangue, and lime used in this test were all taken from southern Hunan, and the coal ash was taken from a coal-fired power plant in Hunan. The microstructure of each material obtained by the SEM test is shown in Figure 1.

The expanded soil was uniformly distributed with some little white calcareous nodules. The microstructure of the expanded soil was mainly flat aggregate and flake particles, and a large number of grains were deposited to form a grain depositing structure. The pores of the soil were of different shapes and nondirectional distribution and had the development trend of pores, providing a channel for water absorption and water loss for expansion and contraction deformation, the appearance of coal gangue is grayish black, the surface structure is hard, and it contains a large number of detritus tiny particles and irregular block structure with obtuse angle, and the surface is uneven. The fly ash is grey powdery, and its microstructure is mainly spherical particles with a small amount of slag particles and debris. Lime is a fine white powder solid with small crystal grain size and large pore size.

2.1.1. Expansive Soil. The natural moisture content of the soil sample was $15.2 \%$. According to the test rules [19], the physical and mechanical indexes of expansive soil were tested, and its main components were measured by infrared spectroscopy, as shown in Table 1 .

2.1.2. Coal Gangue. According to the requirements of the specification [20], the performance of coal gangue is studied, and its technical indexes and chemical composition are shown in Table 2 . In order to fully stimulate the activity of coal gangue, the coal gangue was ground into powder and mixed into expansive soil according to different proportion.

2.1.3. Fly Ash. The physical performance indexes of fly ash are carried out according to the specification [21], and the test results are shown in Table 3. Oxides in fly ash are the 


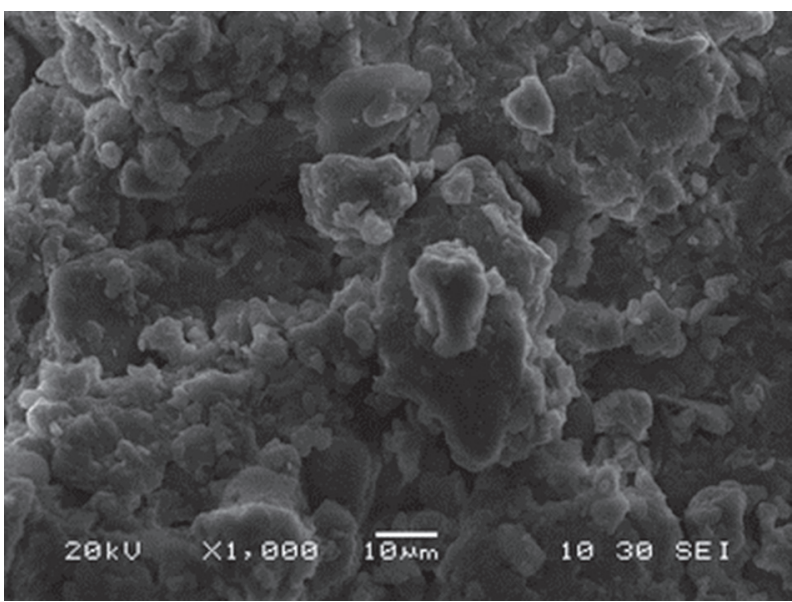

(a)

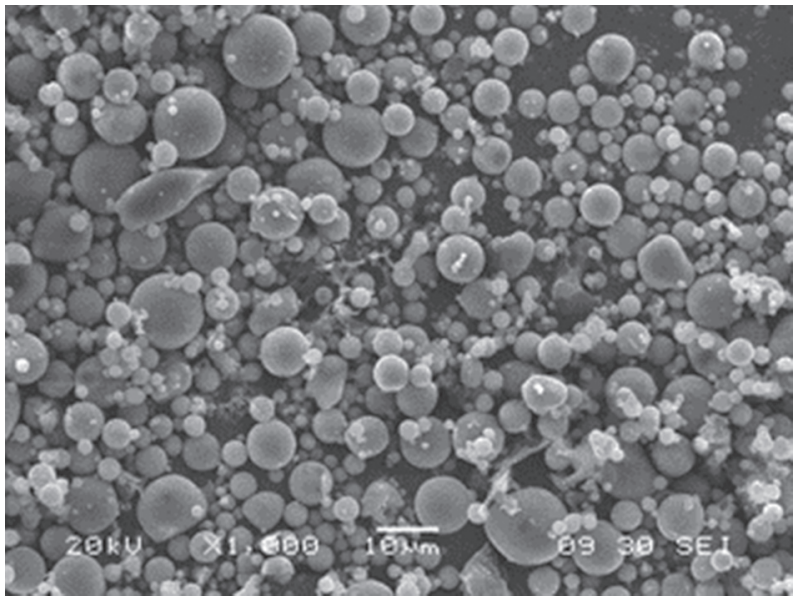

(c)

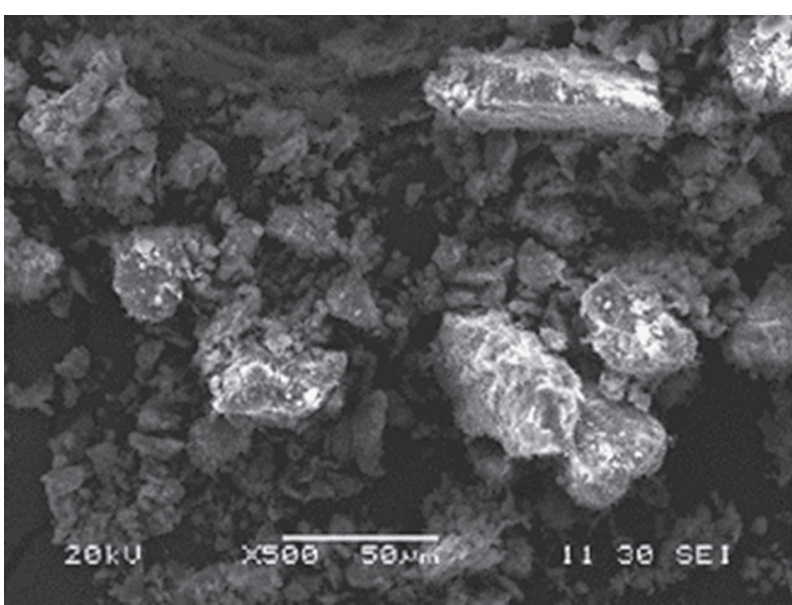

(b)

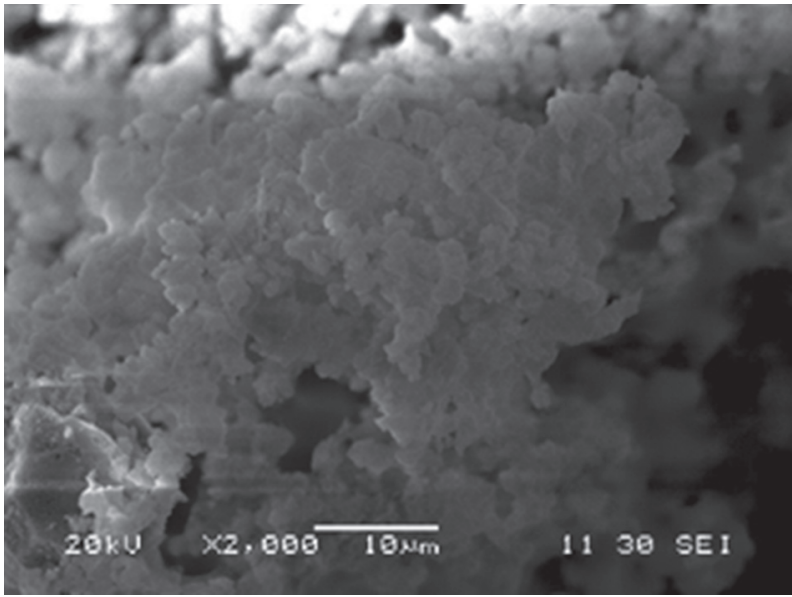

(d)

Figure 1: SEM appearance of materials. (a) Expansive soil. (b) Coal gangue. (c) Fly ash. (d) Lime.

Table 1: Physical index and chemical composition of expansive soil.

\begin{tabular}{|c|c|c|c|c|c|c|}
\hline Physical index & $\begin{array}{c}\text { Liquid limit } \\
(\%) \\
51.50 \\
\end{array}$ & $\begin{array}{c}\text { Plastic limit } \\
(\%) \\
23.56 \\
\end{array}$ & $\begin{array}{c}\text { Plasticity index } \\
(\%) \\
27.94 \\
\end{array}$ & $\begin{array}{c}\text { Maximum dry density } \\
\left(\mathrm{g} \cdot \mathrm{cm}^{-3}\right) \\
1.80 \\
\end{array}$ & $\begin{array}{c}\text { Free swelling rate } \\
(\%) \\
53.1 \\
\end{array}$ & $\begin{array}{c}\text { Optimum moisture } \\
\text { content }(\%) \\
19.0 \\
\end{array}$ \\
\hline $\begin{array}{l}\text { Chemical } \\
\text { composition }\end{array}$ & $\begin{array}{c}\mathrm{SiO}_{2}(\%) \\
45.5\end{array}$ & $\begin{array}{c}\mathrm{Al}_{2} \mathrm{O}_{3}(\%) \\
26.4\end{array}$ & $\begin{array}{c}\mathrm{Fe}_{2} \mathrm{O}_{3}(\%) \\
11.1\end{array}$ & $\begin{array}{c}\mathrm{CaO}(\%) \\
0.25\end{array}$ & $\begin{array}{c}\mathrm{MgO}(\%) \\
1.6\end{array}$ & $\begin{array}{c}\mathrm{K}_{2} \mathrm{O}(\%) \\
2.4\end{array}$ \\
\hline
\end{tabular}

TABle 2: Physical index and chemical composition of coal gangue.

\begin{tabular}{|c|c|c|c|c|c|c|}
\hline Physical index & $\begin{array}{c}\text { Rate of disintegration } \\
(\%) \\
0.5\end{array}$ & $\begin{array}{c}\text { Ignition loss rate } \\
\qquad(\%) \\
15.2\end{array}$ & $\begin{array}{c}\text { Free swelling rate } \\
(\%) \\
13.7\end{array}$ & $\begin{array}{c}\text { Water absorption } \\
(\%) \\
0.5\end{array}$ & $\begin{array}{c}\text { Crushing value } \\
(\%) \\
21.1\end{array}$ & $\begin{array}{c}\text { Strong values } \\
(\%) \\
12\end{array}$ \\
\hline Chemical & $\mathrm{SiO}_{2}(\%)$ & $\mathrm{Al}_{2} \mathrm{O}_{3}(\%)$ & $\mathrm{Fe}_{2} \mathrm{O}_{3}(\%)$ & $\mathrm{CaO}(\%)$ & $\mathrm{MgO}(\%)$ & C (\%) \\
\hline composition & 63.2 & 23.9 & 3.7 & 1.9 & 1.4 & 3.1 \\
\hline
\end{tabular}

TABLe 3: Physical performance index of fly ash.

\begin{tabular}{lccccccc}
\hline Physical index & $\begin{array}{c}\text { Specific surface } \\
\text { area }\left(\mathrm{m}^{2} \cdot \mathrm{g}^{-1}\right)\end{array}$ & $\begin{array}{c}\text { Density } \\
\left(\mathrm{kg} \cdot \mathrm{m}^{-3}\right)\end{array}$ & $\begin{array}{c}\text { Packing } \\
\text { density } \\
\left(\mathrm{kg} \cdot \mathrm{m}^{-3}\right)\end{array}$ & $\begin{array}{c}\text { Loss on } \\
\text { ignition (\%) }\end{array}$ & $\begin{array}{c}\text { Fineness }(45 \mu \mathrm{m} \\
\text { triage) }(\%)\end{array}$ & $\begin{array}{c}\text { Water } \\
\text { absorption }(\%)\end{array}$ & $\begin{array}{c}\text { Standard consistency } \\
\text { of raw ash }(\%)\end{array}$ \\
\hline Chemical & 0.43 & 1868 & 764 & 7.9 & 21 & 101 & 52.3 \\
composition & $\mathrm{SiO}_{2}(\%)$ & $\mathrm{Al}_{2} \mathrm{O}_{3}(\%)$ & $\mathrm{Fe}_{2} \mathrm{O}_{3}(\%)$ & $\mathrm{CaO}(\%)$ & $\mathrm{K}_{2} \mathrm{O}(\%)$ & $\mathrm{Na}_{2} \mathrm{O}(\%)$ & 0.88 \\
\hline
\end{tabular}


main source and element of its activity, accounting for more than $70 \%$ and belonging to class $\mathrm{F}$ fly ash. $\mathrm{CaO}$ content does not exceed $10 \%$, which also belongs to low calcium fly ash.

2.1.4. Lime. The hydrated lime [22] used in this test is slightly soluble in water and can react with $\mathrm{CO}_{2}$ in the air to form calcium carbonate. Its microstructural crystallization has smaller grain size and larger pores. Its physical performance indexes are shown in Table 4.

2.2. Orthogonal Experiment. Orthogonal experiment is an efficient and economical design method to deal with multifactor experimental problems [23]. Based on the experimental data and considering 3 factors and 3 levels, $L_{9}\left(3^{4}\right)$ orthogonal table was selected to determine the mixture ratio design scheme of the three admixtures of improved expansive soil, as shown in Table 5, where Group 0 means the test of expansive soil without any admixtures. The Null column of the header of Table 5 is the error influence term.

\subsection{Test Methods}

2.3.1. Compaction Test. According to T0131-2007 method [19], dry soil method was used to prepare samples, and $5 \mathrm{~mm}$ sieve was used to make the soil properties consistent. A small amount of sand and gravel was removed from the soil. Five soil samples with different moisture content were prepared for each group, and water was added at $2 \%$ increment.

2.3.2. Liquid and Plastic Limits Test. The T0118-2007 method [19] was adopted to pass the different lime soil samples after compaction (one week after ash mixing, let them fully react) through $0.5 \mathrm{~mm}$ sieve. The experiment was carried out with a $100 \mathrm{~g}$ cone and a $30^{\circ}$ cone Angle digital display combined soil liquid plastic limit measuring instrument. The coning depth of point A (liquid limit) was controlled to be $20 \pm 0.2 \mathrm{~mm}$, the coning depth of point B (between liquid plastic limit) was controlled to be $9-11 \mathrm{~mm}$, and the coning depth of point $\mathrm{C}$ (plastic limit) was controlled to be about $3 \mathrm{~mm}$.

2.3.3. Free Expansive Test. According to the T0124-1993 method [19], after one week of compaction, different lime soil samples were smashed with a wood hammer, screened over $0.5 \mathrm{~mm}$, dried, and cooled to room temperature, and then a free expansion rate test was conducted. Readings (accurate to $0.1 \mathrm{ml}$ ) will be taken after the soil sample is settled in the measuring cylinder, and the volume change of the soil sample will be recorded every $3 \mathrm{~h}$ until the volume change of the soil sample is less than $0.2 \mathrm{ml}$, which means that the expansion is stable, and the measurement will stop. The difference between the two parallel measurements shall be less than $5 \%$; otherwise, the test shall be repeated.

2.3.4. Direct Shear Test. According to the T0141-1993 method [19], the soil samples were sifted by $2 \mathrm{~mm}$, and the soil samples of each group were prepared according to the optimal moisture content. Plastic bags were used for one week to make the mixture fully react, and then compaction was conducted. Samples were taken with Vaseline coated ring cutter, and 5 specimens (one for later use) were taken from each group to conduct a direct shear test to determine the shear strength index of each mixture.

2.3.5. Unconfined Compressive Strength Test. According to the T0148-1993 method [19], the test soil sample was the same as the soil sample used in the direct shear test. After compaction of samples with different mixing ratios by compaction instrument, the specimens were made into cylinders with a diameter of $15.2 \mathrm{~cm}$ and a height of $12 \mathrm{~cm}$, which were sealed with plastic bags and put into a curing box with constant temperature and humidity $\left(22^{\circ} \mathrm{C}, 70 \%\right.$ relative humidity) for seven days.

2.3.6. SEM Test. SEM is used to observe the morphology of the sample according to the secondary electronic signal imaging technology, and various effects are generated through the interaction between electron beam and the sample to obtain the microstructure and arrangement rule of the soil sample [24]. In the preparation of the test sample, the lime soil, which has been cured for a week after compaction according to the optimal moisture content, is mashed with a wooden hammer, dried naturally, passed a $0.5 \mathrm{~mm}$ sieve, and packed in a sealed bag. After the sample is made, the SEM test is used to observe the microstructure of the improved soil and analyze its improvement mechanism. In order to make the sample have good electrical conductivity, the sample holder was put into the steaming gold chamber, air was evacuated, and the conductive layer was steamed and plated for 5 minutes.

\section{Results and Discussions}

\subsection{Basic Physical Performance Analysis}

3.1.1. Maximum Dry Density and Optimal Moisture Content. From Table 6 and Figure 2, the best of the expansive soil moisture content was $19 \%$, the best moisture content is in the range of $15.1 \% \sim 18 \%$ with lime soil, expansive soil after the best moisture content is less than the element of adding in lime soil, due to the mixing lime soil through ion exchange, and the electric double layer thickness around the soil particles was reduced, so that more close contact between soil particles (which is called flocculation) results in the decrease of optimum moisture content of soil [25]. The maximum dry density of each ash admixture is lower than that of plain soil, mainly because the following [26]. First, the relative volume mass of the admixture is lower than that of plain expansive soil. Second, it has a certain cementing effect, and the new cementing substance reduces the compaction characteristic of the mixed lime soil, which leads to the decrease of dry density.

The optimum mean value and range of moisture content of each factor and level are calculated by formula and orthogonal design assistant. In order to more intuitively 
TABle 4: Physical properties of lime.

\begin{tabular}{lcccc}
\hline $\begin{array}{l}\text { Density } \\
\left(\mathrm{kg} \cdot \mathrm{m}^{-3}\right)\end{array}$ & $\begin{array}{c}45 \mu \mathrm{m} \text { triage } \\
(\%)\end{array}$ & $\begin{array}{c}\text { The moisture content } \\
(\%)\end{array}$ & $\begin{array}{c}\text { Specific surface area } \\
\left(\mathrm{m}^{2} \cdot \mathrm{kg}^{-1}\right)\end{array}$ & $\begin{array}{c}\text { Ignition loss rate }(\%) \\
\mathrm{Ca}(\mathrm{OH})_{2} \text { content } \\
(\%)\end{array}$ \\
\hline 1810 & 29.7 & 0.15 & 397 & 27.1 \\
\hline
\end{tabular}

TABLE 5: $L_{9}\left(3^{4}\right)$ orthogonal test scheme.

\begin{tabular}{|c|c|c|c|c|}
\hline \multirow[b]{2}{*}{ Group number } & \multicolumn{4}{|c|}{ Factors } \\
\hline & A (coal gangue) $\%$ & B (fly ash) \% & C (lime) \% & Null column \\
\hline 0 & 0 & 0 & 0 & - \\
\hline 1 & 6 & 7 & 2 & 1 \\
\hline 2 & 6 & 9 & 4 & 2 \\
\hline 3 & 6 & 11 & 6 & 3 \\
\hline 4 & 8 & 7 & 4 & 3 \\
\hline 5 & 8 & 9 & 6 & 1 \\
\hline 6 & 8 & 11 & 2 & 2 \\
\hline 7 & 10 & 7 & 6 & 2 \\
\hline 8 & 10 & 9 & 2 & 3 \\
\hline 9 & 10 & 11 & 4 & 1 \\
\hline
\end{tabular}

TABLE 6: Optimum moisture content and maximum dry density.

\begin{tabular}{lcccccccccc}
\hline Test number & 0 & 1 & 2 & 3 & 4 & 5 & 6 & 7 & 8 & 9 \\
\hline Maximum dry density $(\%)$ & 19.0 & 17.9 & 16.7 & 16.2 & 16.8 & 15.1 & 15.7 & 16.8 & 17.3 & 15.2 \\
Maximum dry density $\left(\mathrm{g} / \mathrm{cm}^{3}\right)$ & 1.80 & 1.79 & 1.77 & 1.73 & 1.77 & 1.74 & 1.75 & 1.72 & 1.74 & 1.75 \\
\hline
\end{tabular}

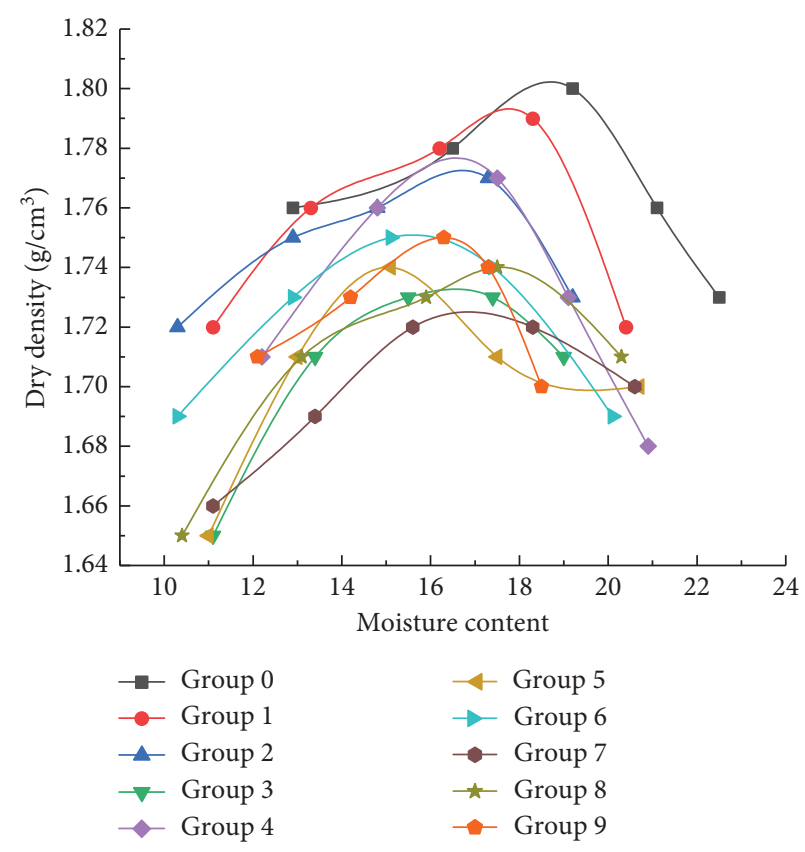

Figure 2: Curve of relationship between moisture content and dry density.

understand the influence of each admixture on the test results, the trend diagram of the relationship between each factor and the index results is drawn, as shown in Figure 3. The fly ash content is the main factor affecting the optimal moisture content of expansive soil, followed by the coal gangue powder content.
In order to analyze the importance of each factor to the test results, the Analysis of Variance (ANOVA) table was obtained according to the variance analysis of compaction test data by formula and orthogonal design assistant, as shown in Table 7.

It can be seen from the ANOVA table of optimal water content that the $\mathrm{F}$ ratio of the three factors is not greater than $\mathrm{F}_{0.1}$ critical value 9 (which can be obtained from tables in reference [27]), indicating that the effect of the three factors on the optimal water content of expansive soil is not significant. The F ratio of fly ash is 4.397 , which is greater than $\mathrm{F}_{0.25}(2,2)=3$, indicating that it has a certain influence on the test results, and the results are the same as the range analysis. The error estimate of the Null column shows that the error does not affect the test result, and the test result is reliable.

3.1.2. Analysis of Liquid Plastic Limit Index. It can be seen from Figure 4 that both the liquid limit and plastic index of the ash-doped soil are lower than those of the expansive soil, while the plastic limit of the expansive soil is higher than that of the ash-doped soil. The reason is that clay content and mineral hydrophilicity are the reflection of soil plasticity. The plasticity index of expansive soil decreases after ash addition, which indicates that clay content and hydrophilicity of soil particles decrease. As a result, the diffusion layer of soil particles becomes thinner, the binding water decreases, and the plasticity of soil decreases. Studies in reference [28] showed that the lower the plasticity index, the worse the expansibility of soil.

According to Figure 5, with the increase of the three factors, the plastic index of expansive soil decreases. Among 


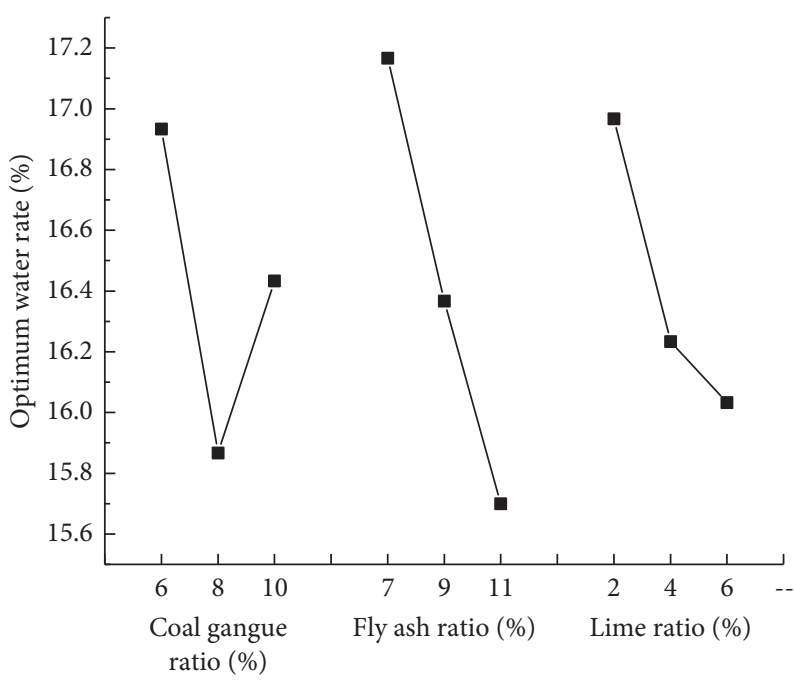

Figure 3: Trend chart of optimum moisture content.

TABLE 7: ANOVA table for optimum moisture content.

\begin{tabular}{|c|c|c|c|c|c|c|}
\hline Factors & Square of deviance & Degree of freedom & Mean square & F ratio & F critical value & Significant \\
\hline Coal gangue & 1.709 & 2 & 0.8545 & 2.322 & $\mathrm{~F}_{0.01}(2,2)=99$ & \\
\hline Fly ash & 3.236 & 2 & 1.618 & 4.397 & $\mathrm{~F}_{0.05}(2,2)=19$ & $\mathrm{O}$ \\
\hline Lime & 1.449 & 2 & 0.7245 & 1.969 & $\mathrm{~F}_{0.1}(2,2)=9$ & \\
\hline Error & 0.736 & 2 & 0.368 & & $\mathrm{~F}_{0.25}(2,2)=3$ & \\
\hline Sum & 7.13 & 8 & & & & \\
\hline
\end{tabular}

In ANOVA, if the mean square value of a factor is less than or equal to the error mean square, it will be treated as the error term, and $\mathrm{F}$ value will not be calculated, where " $* * *$ " means very significant $P<0.01$, “** " means significant $0.01 \leq P<0.05$, “*” means relatively significant $0.05 \leq P<0.01$, and "O" means that $0.1 \leq P<0.25$ has a certain influence.

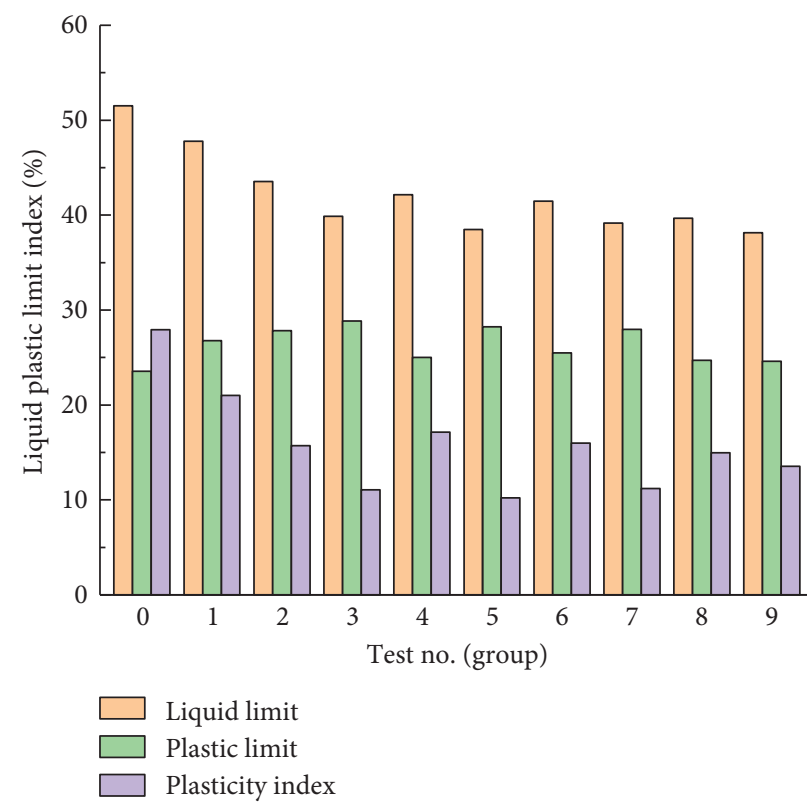

FIgURE 4: Results of liquid plastic limit indices.

them, there is an approximate linear relationship between the coal gangue content and the lime content, and the plastic index of expansive soil has the greatest influence on the plastic index of expansive soil. It can be judged that the content of lime is the main factor affecting the plasticity index of expansive soil, followed by fly ash and coal gangue.

It can be seen from Table 8 that the $F$ ratio of lime content and fly ash content both is greater than $\mathrm{F}_{0.05}(2,2)=$ 


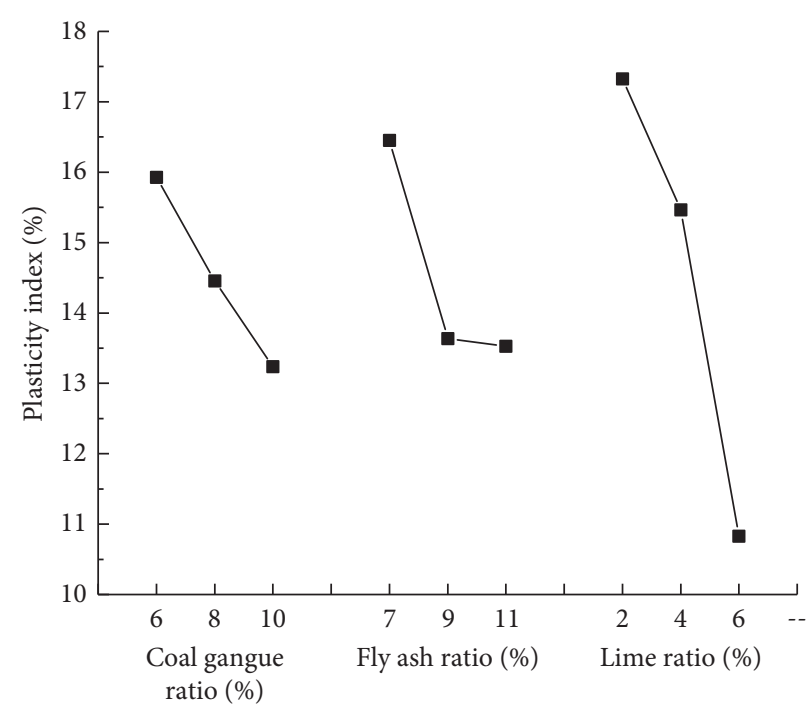

FIgURE 5: Trend chart of plasticity index.

TABLE 8: ANOVA table for plasticity index.

\begin{tabular}{lcccccc}
\hline Factors & Square of deviance & Degree of freedom & Mean square & F ratio & F critical value & Significant \\
\hline Coal gangue & 10.887 & 2 & 5.4435 & 15.553 & $\mathrm{~F}_{0.01}(2,2)=99$ & $*$ \\
Fly ash & 16.511 & 2 & 8.2555 & 23.587 & $\mathrm{~F}_{0.05}(2,2)=19$ & $* *$ \\
Lime & 67.221 & 2 & 33.6105 & 96.030 & $\mathrm{~F}_{0.1}(2,2)=9$ \\
Error & 0.700 & 2 & 0.350 & & $\mathrm{~F}_{0.25}(2,2)=3$ \\
Sum & 95.32 & 8 & & & & \\
\hline
\end{tabular}

In ANOVA, if the mean square value of a factor is less than or equal to the error mean square, it will be treated as the error term, and $\mathrm{F}$ value will not be calculated, where “***" means very significant $P<0.01$, “** " means significant $0.01 \leq P<0.05$, “*” means relatively significant $0.05 \leq P<0.1$, and “O” means that $0.1 \leq P<0.25$ has a certain influence.

9, indicating that these two factors have a significant influence on the plasticity index of expansive soil. Among them, the F ratio of lime is 96.030 , which is very significant. The content factor of gangue powder is relatively significant, and its influence on the plasticity index of expansive soil is as follows: lime $>$ fly ash $>$ coal gangue.

3.1.3. Analysis of Free Expansion Rate. According to Figure 6, the free expansion rate decreases with the increase of fly ash and lime content. With the increase of the content of gangue powder, the free expansion first decreases and then increases. As a result of the excess content of gangue powder, some of the gangue powder has not yet fully reacted after the interaction and hardening effect, and it has certain expansibility, which leads to the increase of the free expansion and springback rate of soil particles. The main factor affecting the free expansion rate of expansive soil is the content of lime, and the coal gangue powder is the secondary factor. When the proportion of coal gangue powder $\mathrm{A}_{2}$ is $8 \%$, the proportion of fly ash $\mathrm{B}_{3}$ is $11 \%$, and the proportion of lime $\mathrm{C}_{3}$ is $6 \%$, and the improvement effect of free expansion rate of expansive soil is the best. The optimal scheme is $\mathrm{A}_{2} \mathrm{~B}_{3} \mathrm{C}_{3}$.

Table 9 shows that coal gangue powder, fly ash, and lime content have significant effects on the free expansion rate of expansive soil. The maximum $\mathrm{F}$ ratio of lime is $49.998 \mathrm{~F}$, and the minimum $\mathrm{F}$ ratio of fly ash is 38.932 . The primary and secondary results of factors are the same as the results of range analysis. The error of the Null column is very small, which means that it does not affect the test result, and the test result is reliable.

\subsection{Mechanical Property Analysis}

3.2.1. Analysis of Shear Strength Index. It can be seen from the correlation coefficient $R$ in Figure 7 and Table 10 that the linear correlation of data is highly significant. The shear strength index of the mixed soil has been greatly improved, among which the cohesion has been increased by $101.7 \mathrm{kPa}$ to the maximum, the internal friction Angle has been increased by $18.1^{\circ}$ to the maximum, and the shear strength has also been greatly improved, indicating that the improvement effect is good. Due to expansive soil mixed ash, Ion exchange, agglomeration, and gelation will occur [25], and silica and aluminum in expansive soil will react chemically with admixture to form some strong bonding materials like $\mathrm{CaSiO}_{3}$ and $\mathrm{CaO} \cdot \mathrm{Al}_{2} \mathrm{O}_{3}$ and so on, which makes structure of the expansive soil and interactions between soil particles enhanced, some fine grain become coarse particles, and interparticle friction increase. Thus, the interface slippage between particles can be prevented when shear action occurs, the internal friction angle increases, and the cohesion and strength increase. 


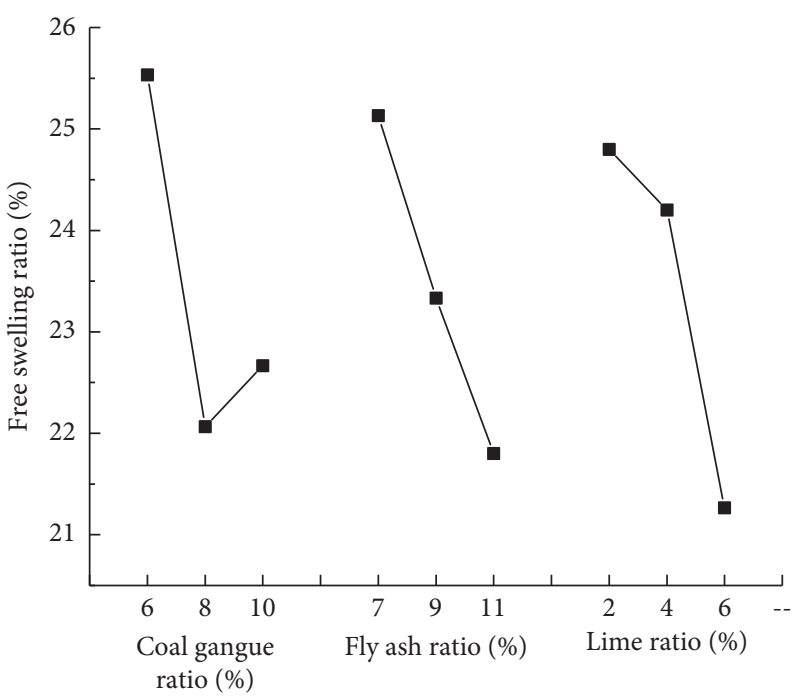

Figure 6: Trend diagram of free expansion rate.

TABLE 9: ANOVA table for free expansion rate.

\begin{tabular}{lcccccc}
\hline Factors & Square of deviance & Degree of freedom & Mean square & F ratio & F critical value & Significant \\
\hline Coal gangue & 20.596 & 2 & 10.298 & 48.009 & $\mathrm{~F}_{0.01}(2,2)=99$ & $* *$ \\
Fly ash & 16.702 & 2 & 8.351 & 38.932 & $\mathrm{~F}_{0.05}(2,2)=19$ & $* *$ \\
Lime & 21.449 & 2 & 10.7245 & 49.998 & $\mathrm{~F}_{0.1}(2,2)=9$ \\
Error & 0.429 & 2 & 0.2145 & & $\mathrm{~F}_{0.25}(2,2)=3$ \\
Sum & 59.18 & 8 & & & \\
\hline
\end{tabular}

In ANOVA, if the mean square value of a factor is less than or equal to the error mean square, it will be treated as the error term, and $\mathrm{F}$ value will not be calculated, where “***" means very significant $P<0.01$, “** " means significant $0.01 \leq P<0.05$, “*” means relatively significant $0.05 \leq P<0.1$, and "O" means that $0.1 \leq P<0.25$ has a certain influence.

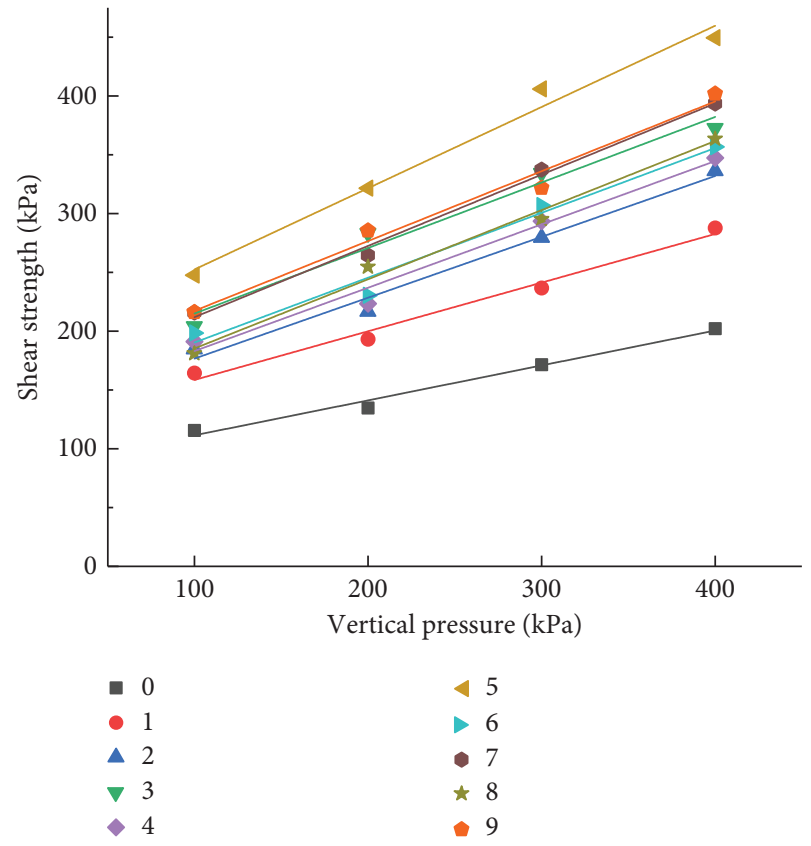

FIGURE 7: Relationship between shear strength and vertical pressure.
It can be seen from the trend in Figure 8 that the degree of influence of different factors is different, among which the primary and secondary factors affecting the shear strength of expansive soil are the largest lime, followed by coal gangue powder. When the proportion of gangue powder is $8 \%$, the shear strength reaches the maximum. When the content of gangue powder continues to increase, the addition of excess gangue powder is equivalent to the addition of silt into expansive soil, which has no cohesive force, resulting in the decrease of soil strength. When the proportion of fly ash increases from $7 \%$ to $11 \%$, and the proportion of lime increases from $2 \%$ to $6 \%$, the shear strength of expansive soil increases gradually without a peak, indicating that the content of fly ash and lime still has room to rise. However, for this orthogonal experiment, the optimal scheme is $\mathrm{A}_{2} \mathrm{~B}_{3} \mathrm{C}_{3}$.

According to Table 11, the $\mathrm{F}$ ratio of three mixtures were less than $\mathrm{F}_{0.1}$ which is equal to 9 , which shows that three mixtures' influence on shear strength of expansive soil is not significant, and the dosage of lime has effects on shear strength, and lime, which is equal to 5.709 , is greater than that of coal gangue powder, which is equal to 2.737 , and $\mathrm{F}$ ratio of fly ash, which is equal to 0.971 , is very small to be neglected. The effect of lime on the shear strength of 
TABLE 10: Results of direct shear test.

\begin{tabular}{|c|c|c|c|c|c|c|}
\hline $\begin{array}{l}\text { Sample } \\
\text { number }\end{array}$ & Fitting equation & $\begin{array}{l}\text { Cohesive force } \\
\quad c(\mathrm{kPa})\end{array}$ & $\begin{array}{l}\text { Internal friction } \\
\text { angle } \varphi\left(\left(^{\circ}\right)\right.\end{array}$ & $\begin{array}{l}\text { Shear strength } \tau(\mathrm{kPa}) \text { (the } \\
\text { normal stress is } 100 \mathrm{kPa} \text { ) }\end{array}$ & $\begin{array}{l}\text { Correlation } \\
\text { coefficient } r\end{array}$ & $\begin{array}{l}\text { Correlation } \\
\text { index } R^{2}\end{array}$ \\
\hline 0 & $\tau=0.297 \sigma+81.75$ & 81.75 & $16.5^{\circ}$ & 115.5 & 0.9931 & 0.9794 \\
\hline 1 & $\tau=0.4136 \sigma+117.2$ & 117.2 & $22.5^{\circ}$ & 164.5 & 0.9926 & 0.9779 \\
\hline 2 & $\tau=0.5175 \sigma+124.95$ & 124.95 & $27.4^{\circ}$ & 184.7 & 0.9919 & 0.9759 \\
\hline 3 & $\tau=0.5571 \sigma+159.3$ & 159.3 & $29.1^{\circ}$ & 204.0 & 0.9863 & 0.9593 \\
\hline 4 & $\tau=0.5385 \sigma+129.25$ & 129.25 & $28.3^{\circ}$ & 191.2 & 0.9910 & 0.9732 \\
\hline 5 & $\tau=0.6906 \sigma+183.45$ & 183.45 & $34.6^{\circ}$ & 247.5 & 0.9924 & 0.9774 \\
\hline 6 & $\tau=0.5512 \sigma+135.25$ & 135.25 & $28.9^{\circ}$ & 198.3 & 0.9894 & 0.9684 \\
\hline 7 & $\tau=0.6058 \sigma+151.35$ & 151.35 & $31.2^{\circ}$ & 215.8 & 0.9974 & 0.9923 \\
\hline 8 & $\tau=0.5879 \sigma+126.55$ & 126.55 & $30.5^{\circ}$ & 180.9 & 0.9944 & 0.9832 \\
\hline 9 & $\tau=0.5935 \sigma+157.95$ & 157.95 & $30.7^{\circ}$ & 216.1 & 0.9908 & 0.9725 \\
\hline
\end{tabular}

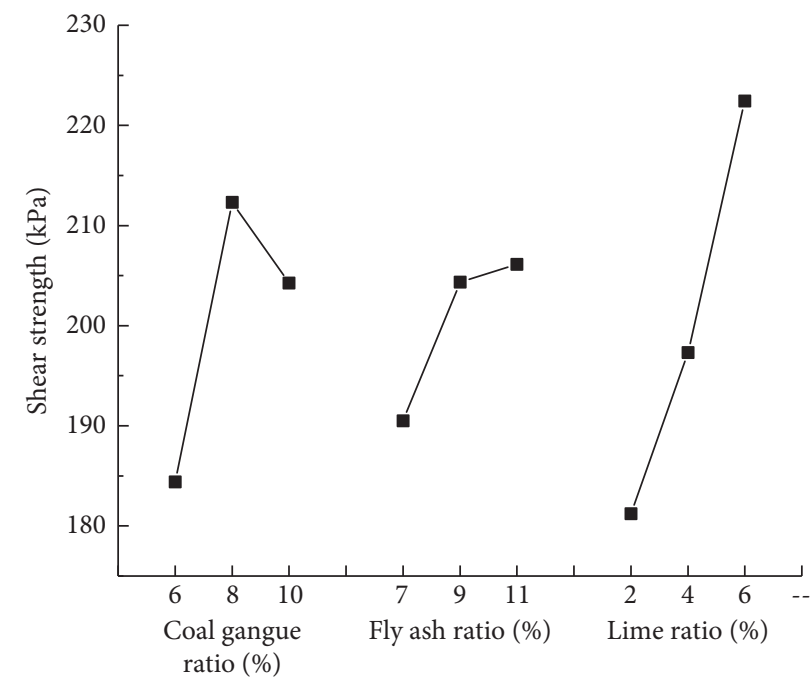

Figure 8: Trend chart of shear strength.

TABLE 11: ANOVA table for shear strength.

\begin{tabular}{|c|c|c|c|c|c|c|}
\hline Factors & Square of deviance & Degree of freedom & Mean square & F ratio & F critical value & Significant \\
\hline Coal gangue & 1240.027 & 2 & 620.0135 & 2.737 & $\mathrm{~F}_{0.01}(2,2)=99$ & \\
\hline Fly ash & 439.807 & 2 & 219.9035 & 0.971 & $\mathrm{~F}_{0.05}(2,2)=19$ & \\
\hline Lime & 2586.660 & 2 & 1293.33 & 5.709 & $\mathrm{~F}_{0.1}(2,2)=9$ & $\mathrm{O}$ \\
\hline Error & 453.087 & 2 & 226.5435 & & $\mathrm{~F}_{0.25}(2,2)=3$ & \\
\hline Sum & 4719.58 & 8 & & & & \\
\hline
\end{tabular}

In ANOVA, if the mean square value of a factor is less than or equal to the error mean square, it will be treated as the error term, and $\mathrm{F}$ value will not be calculated, where "***" means very significant $P<0.01$, “** " means significant $0.01 \leq P<0.05$, “*” means relatively significant $0.05 \leq P<0.01$, and "O" means that $0.1 \leq P<0.25$ has a certain influence.

expansive soil is greater than that of coal gangue powder and fly ash, showing poor results. The error of the Null column does not affect the test result, and the test result is reliable.

3.2.2. Analysis of Unconfined Compressive Strength Index. Table 12 shows that the unconfined compressive strength of the expansive soil after ash addition is significantly increased, and the maximum increase is nearly double. The reason is that both the expansive soil and the material in the admixture have a hard coagulation reaction to form a kind of strong viscous cementing material, which improves the unconfined compressive strength of the expansive soil.
In Figure 9, average unconfined compressive strength and level of various factors trend diagram shows that when the proportion of coal gangue powder is $8 \%$, the unconfined compressive strength, the largest $11 \%$ of fly ash and lime proportion was $6 \%$, the unconfined compressive strength reached maximum, and mixing the unconfined compressive strength of lime soil with fly ash and lime proportion is approximate linear relationship, it showed that the dosage of fly ash is $11 \%$, when dosage of lime is $6 \%$, not necessarily belonging to the best content, but from the current test, the optimum scheme is $\mathrm{A}_{2} \mathrm{~B}_{3} \mathrm{C}_{3}$.

In Table 13, the dosage of lime and coal gangue powder content $\mathrm{F}$ were greater than $\mathrm{F}_{0.01}(2,2)=99$, suggesting that 
TABLE 12: Results of unconfined compressive strength test.

\begin{tabular}{|c|c|c|c|c|c|c|c|c|c|c|}
\hline Test number & 0 & 1 & 2 & 3 & 4 & 5 & 6 & 7 & 8 & 9 \\
\hline Unconfined compressive strength $/ \mathrm{kPa}$ & 733.5 & 965.51 & 1060.85 & 1255.38 & 1180.44 & 1353.48 & 1232.24 & 1292.86 & 1150.68 & 1239.95 \\
\hline
\end{tabular}

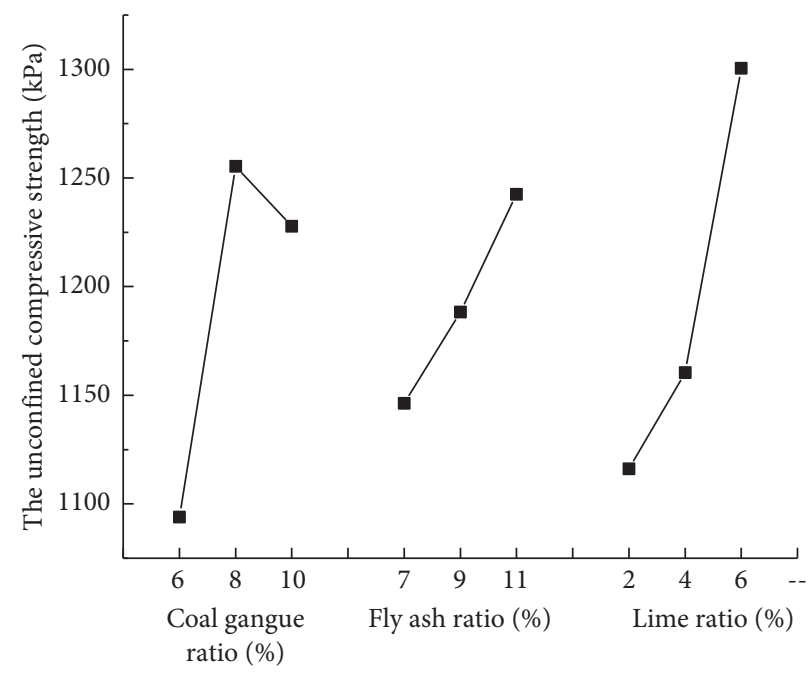

FIGURE 9: Trend chart of unconfined compressive strength.

TABLE 13: ANOVA table for unconfined compressive strength.

\begin{tabular}{lcccccc}
\hline Factors & Square of deviance & Degree of freedom & Mean square & F ratio & F critical value & Significant \\
\hline Coal gangue & 44766.681 & 2 & 22383.341 & 270.513 & $\mathrm{~F}_{0.01}(2,2)=99$ & $* * *$ \\
Fly ash & 13970.503 & 2 & 6985.2515 & 84.420 & $\mathrm{~F}_{0.05}(2,2)=19$ & $* *$ \\
Lime & 55619.083 & 2 & 27809.542 & 336.091 & $\mathrm{~F}_{0.1}(2,2)=9$ & $* *$ \\
Error & 165.488 & 2 & 82.744 & & $\mathrm{~F}_{0.25}(2,2)=3$ \\
Sum & 114521.75 & 8 & & &
\end{tabular}

In ANOVA, if the mean square value of a factor is less than or equal to the error mean square, it will be treated as the error term, and $\mathrm{F}$ value will not be calculated, where "***" means very significant $P<0.01$, “** " means significant $0.01 \leq P<0.05$, “*” means relatively significant $0.05 \leq P<0.1$, and "O" means that $0.1 \leq P<0.25$ has a certain influence.

the dosage of lime and coal gangue powder content factors impact on the rate of free expansion of expansive soil effect is very significant, the dosage of fly ash $\mathrm{F}$ ratio is greater than $\mathrm{F}_{0.05}(2,2)=19$, and its influence is significant, illustrating that different mixing ratio of admixture on the unconfined compressive strength of expansive soil has special effects, and various factors on the unconfined compressive strength of expansive soil influence the sequence of significance of lime powder, coal gangue, and fly ash.

3.3. Comprehensive Analysis. According to the range and variance analysis of each index, it is found that the size of the influencing factors and the optimal scheme of each index are different, so it is necessary to use the comprehensive balance method to comprehensively compare and analyze the results of the multi-index sample and get the size of the influencing factors and the optimal scheme.

Table 14 shows that, with different test indexes, the factors of influence degree and the optimal scheme are also different. Through comprehensive balance method, the influencing factors of modified expansive soil for primary and secondary factors are concluded: $\mathrm{C}>\mathrm{A}>\mathrm{B}$, one of the most optimum schemes for $\mathrm{A}_{2} \mathrm{~B}_{3} \mathrm{C}_{3}$; namely, coal gangue powder content is $8 \%$, dosage of fly ash is $11 \%$, and lime content is $6 \%$.

According to the optimal solution for physical and mechanical properties of composite improved expansive soil basic indicators authentication contrast, as shown in Table 15, the measured results of the test index were improved obviously, which are better than the orthogonal experiment results. It shows that the mixture ratio scheme is reasonable and reliable and can be used as the reference for the optimal mixture ratio of the improved expansive soil subgrade engineering.

3.4. Improvement Mechanism Analysis. Scanning electron microscopy (SEM) is used to conduct scanning tests on 9 sets of different mixture-doped soils, and their microstructure result is shown in Figure 10.

It can be seen from Figures $10(\mathrm{a})-10(\mathrm{~d})$ and $10(\mathrm{f})$ that the microstructures of expansive soil with different mixtures are basically the same. The surface and interior of the soil 
TABLE 14: Multi-index analysis of test results.

\begin{tabular}{|c|c|c|c|c|c|}
\hline Index & & A (coal gangue) & B (fly ash) & C (lime) & $\mathrm{D}$ (null) \\
\hline \multirow{6}{*}{ The plastic index/\% } & $k_{1}$ & 15.927 & 16.453 & 17.327 & 14.930 \\
\hline & $k_{2}$ & 14.453 & 13.637 & 15.463 & 14.300 \\
\hline & $k_{3}$ & 13.237 & 13.527 & 10.827 & 14.387 \\
\hline & Range R & 2.690 & 2.926 & 6.500 & 0.630 \\
\hline & Primary and secondary factors & & $\mathrm{C}>\mathrm{B}>\mathrm{A}$ & & \\
\hline & Optimal solution & & $\mathrm{C}_{3} \mathrm{~B}_{3} \mathrm{~A}_{3}$ & & \\
\hline \multirow{6}{*}{ Free expansion rate $/ \%$} & $k_{1}$ & 25.533 & 25.133 & 24.800 & 23.400 \\
\hline & $k_{2}$ & 22.067 & 23.333 & 24.200 & 23.700 \\
\hline & $k_{3}$ & 22.667 & 21.800 & 21.267 & 23.167 \\
\hline & Range $\mathrm{R}$ & 3.466 & 3.333 & 3.533 & 0.533 \\
\hline & Primary and secondary factors & & $\mathrm{C}>\mathrm{A}>\mathrm{B}$ & & \\
\hline & Optimal solution & & $\mathrm{C}_{3} \mathrm{~A}_{2} \mathrm{~B}_{3}$ & & \\
\hline \multirow{6}{*}{ Shear strength $/ \mathrm{kPa}$} & $k_{1}$ & 184.400 & 190.500 & 181.233 & 209.367 \\
\hline & $k_{2}$ & 212.333 & 204.367 & 197.333 & 199.600 \\
\hline & $k_{3}$ & 204.267 & 206.133 & 222.433 & 192.033 \\
\hline & Range $\mathrm{R}$ & 27.933 & 15.633 & 41.200 & 17.334 \\
\hline & Primary and secondary factors & & $\mathrm{C}>\mathrm{A}>\mathrm{B}$ & & \\
\hline & Optimal solution & & $\mathrm{C}_{3} \mathrm{~A}_{2} \mathrm{~B}_{3}$ & & \\
\hline \multirow{6}{*}{ The unconfined compressive strength $/ \mathrm{kPa}$} & $k_{1}$ & 1093.913 & 1146.270 & 1116.143 & 1186.313 \\
\hline & $k_{2}$ & 1255.387 & 1188.337 & 1160.413 & 1195.317 \\
\hline & $k_{3}$ & 1227.830 & 1242.523 & 1300.573 & 1195.500 \\
\hline & Range $\mathrm{R}$ & 161.474 & 96.253 & 184.430 & 9.187 \\
\hline & Primary and secondary factors & & $\mathrm{C}>\mathrm{A}>\mathrm{B}$ & & \\
\hline & Optimal solution & & $\mathrm{C}_{3} \mathrm{~A}_{2} \mathrm{~B}_{3}$ & & \\
\hline
\end{tabular}

TABLE 15: Physical and mechanical indexes of improved expansive soil.

\begin{tabular}{|c|c|c|c|c|c|c|c|c|}
\hline Test materials & $\begin{array}{c}\text { Liquid } \\
\text { limit }(\%)\end{array}$ & $\begin{array}{c}\text { Plastic } \\
\text { limit (\%) }\end{array}$ & $\begin{array}{c}\text { Plastic } \\
\text { index } \\
(\%)\end{array}$ & $\begin{array}{c}\text { Maximum dry } \\
\text { density } \\
\left(\mathrm{g} \cdot \mathrm{cm}^{-3}\right)\end{array}$ & $\begin{array}{c}\text { Optimum } \\
\text { moisture } \\
\text { content }(\%)\end{array}$ & $\begin{array}{c}\text { Free } \\
\text { expansion } \\
\text { rate }(\%)\end{array}$ & $\begin{array}{c}\text { Shear } \\
\text { strength } \\
(\mathrm{kPa})\end{array}$ & $\begin{array}{l}\text { Unconfined } \\
\text { compressive } \\
\text { strength }(\mathrm{kPa})\end{array}$ \\
\hline $\begin{array}{l}\text { Unimproved } \\
\text { expansive soil }\end{array}$ & 51.5 & 23.56 & 27.94 & 1.80 & 19.0 & 53.1 & 115.5 & 733.50 \\
\hline $\begin{array}{l}\text { Expansive soil } \\
\text { improved by lime }\end{array}$ & 43.41 & 26.74 & 16.67 & 1.66 & 17.84 & 25.7 & 248.4 & 1259.23 \\
\hline $\begin{array}{l}\text { Expansive soil } \\
\text { improved by three } \\
\text { mixtures }\end{array}$ & 38.64 & 28.75 & 9.89 & 1.73 & 16.53 & 17.4 & 279.4 & 1468.72 \\
\hline
\end{tabular}

have obvious boundary planes, which contain a large number of fly ash globular particles, and the flake and flat particles are reduced. The microagglomeration formed by white lime connects the globular particles and the aggregate soil particles, among which the diameter of the globular particles is between $2 \mathrm{~m}$ and $8 \mathrm{~m}$, filling most of the pores and making the pore diameter smaller.

In Figures 10(e) and 10(i), there are many crystal grains of $\mathrm{SiO}_{2}$, white $\mathrm{Ca}(\mathrm{OH})_{2}$ and $\mathrm{CaCO}_{3}$, including less sheet-shape grains, flat particles. The shape of the edge smooth structure of the unit is different, and its orientation is poorer, but connectivity is good, with small pores and different types. The pores are mixed with a few calcareous crystals and spherical particles, laminates and aggregates, and particles and microaggregates are filled in the structural skeleton pores.

In Figures $10(\mathrm{~g})$ and $10(\mathrm{~h})$, regarding the expansive soil in $\mathrm{C}, \mathrm{SiO}_{2}$ and silicon minerals such as calcium stone morphology of coal gangue, rhombohedron shaped, there are many small clay soil surface layers consisting of aggregate, larger aggregate inside, which is composed of single spherical particles, and the microconglomerate, internal to the grain structure, and the microstructure features with aggregate structure are given priority, also including granular pile structure.

From the above analysis, it can be seen that, with different mixing ratios, the aggregate formed by soil is also different, and the surface microstructure of the aggregate will also change. The skeleton structure of the improved soil microstructure is basically composed of aggregate and aggregate, aggregate and flake structure, and the pores in the soil structural skeleton are filled with particles and microaggregates [29]. Different proportions of coal gangue powder, fly ash, and lime admixtures are important factors to improve the microstructure of expansive soil.

When coal gangue powder, fly ash, and lime are mixed into expansive soil, physical and chemical reactions will take place, and the improvement of expansive soil is mainly through four processes, namely, ion exchange, granulation, 


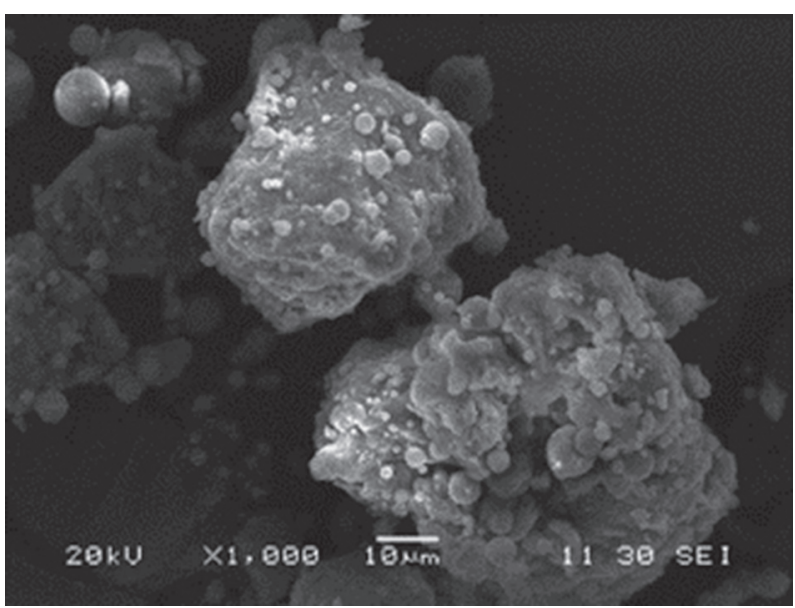

(a)

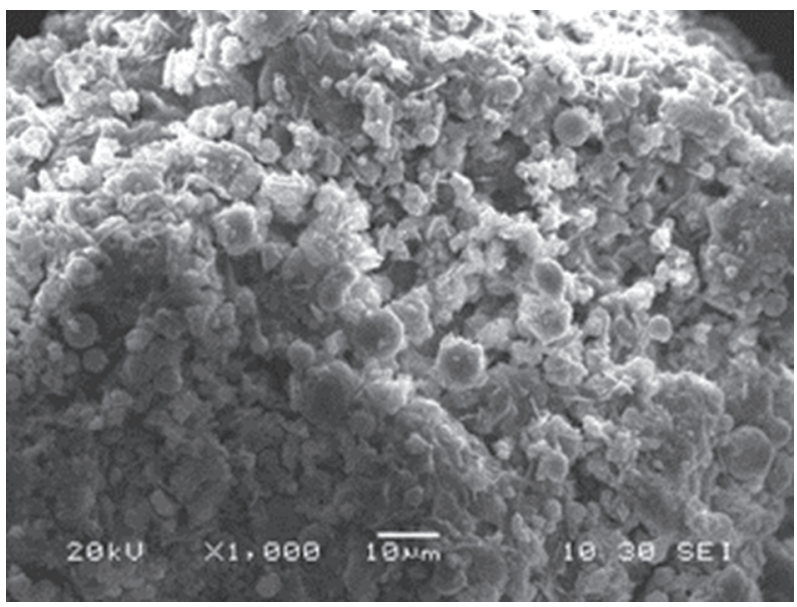

(c)

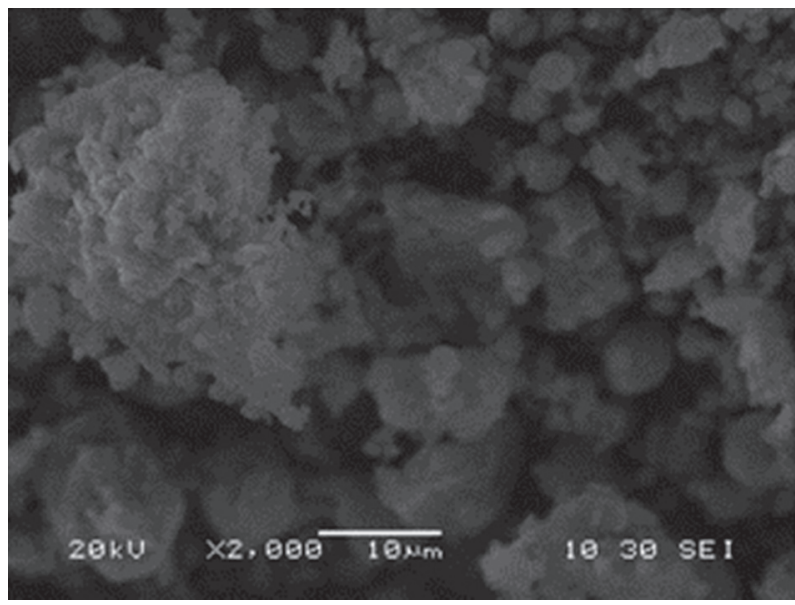

(e)

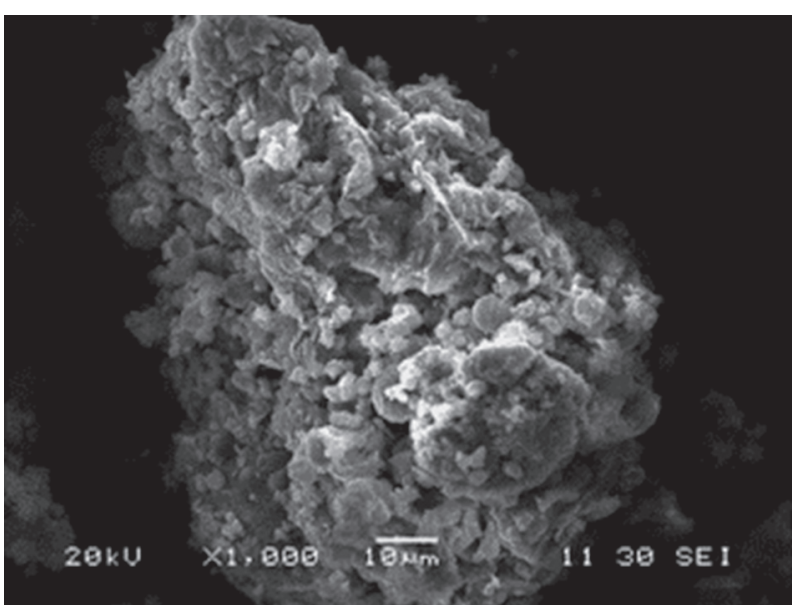

(b)

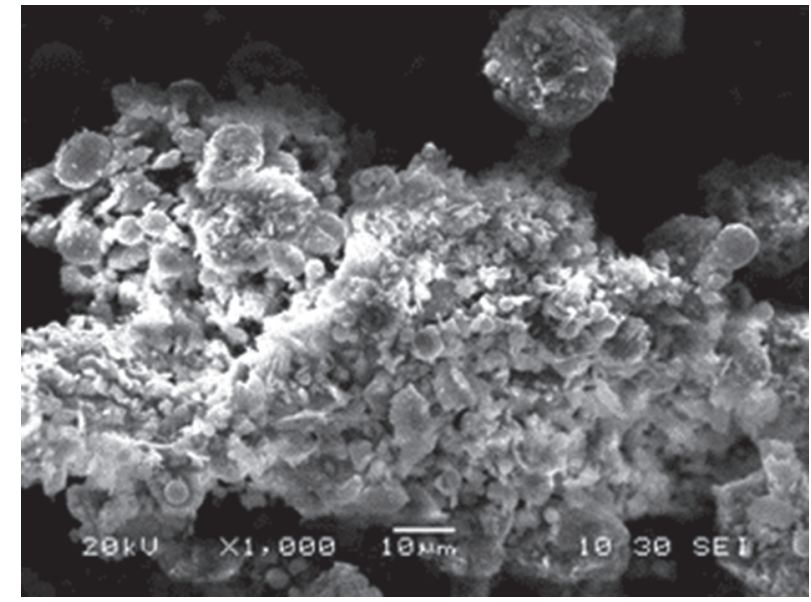

(d)

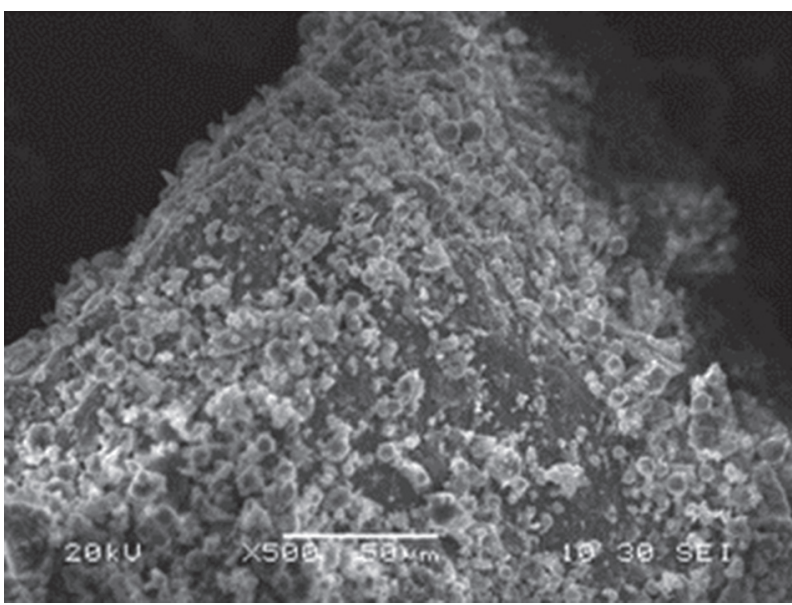

(f)

Figure 10: Continued. 


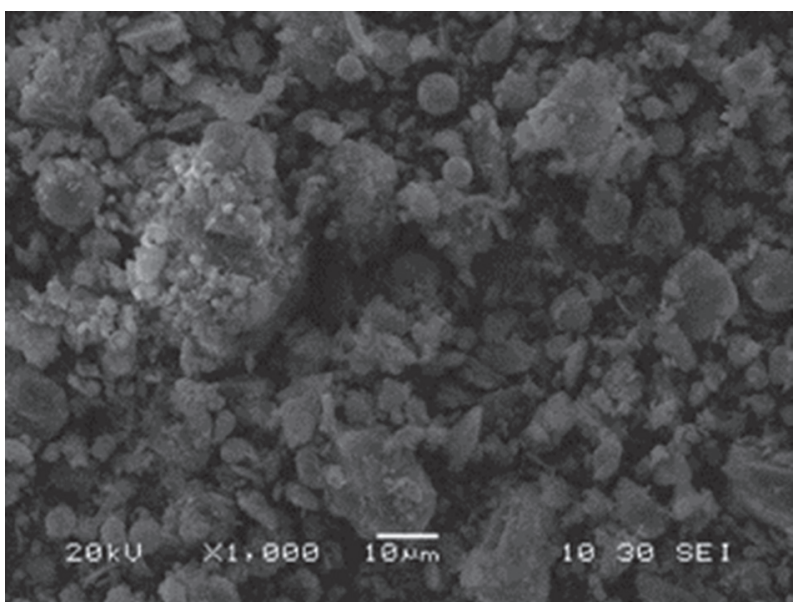

(g)

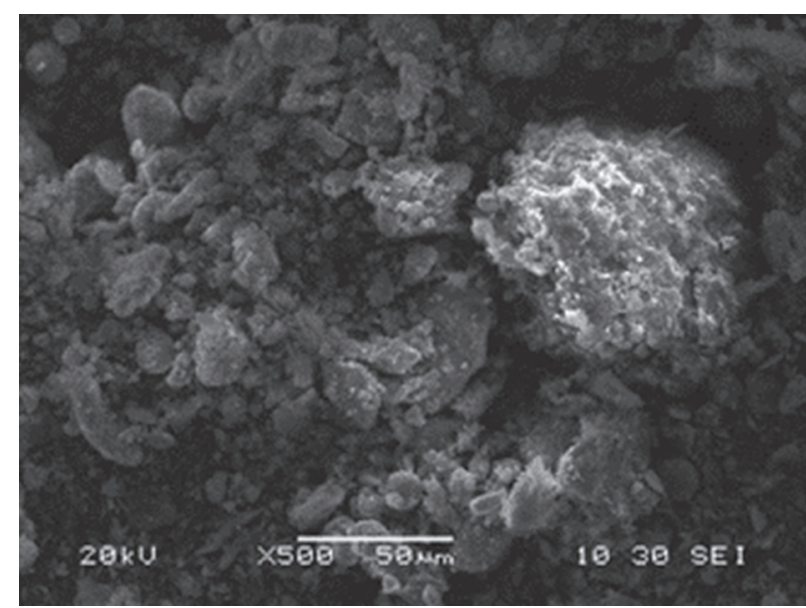

(h)

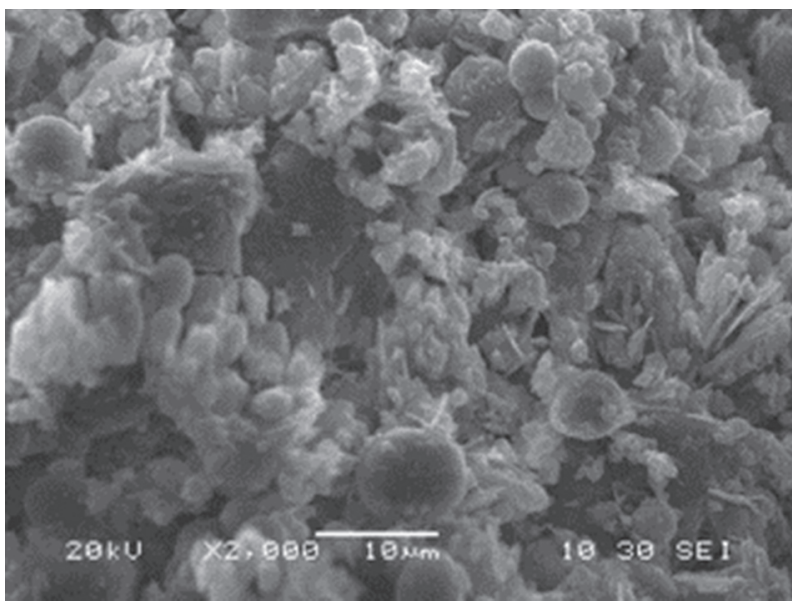

(i)

Figure 10: SEM of expansive soil with different mixtures. (a) The 1st group of soil sample. (b) The 2nd group of soil sample. (c) The 3rd group of soil sample. (d) The 4 th group of soil sample. (e) The 5 th group of soil sample. (f) The 6 th group of soil sample. (g) The 7 th group of soil sample. (h) The 8 th group of soil sample. (i) The 9th group of soil sample.

carbonation, and gelation [30, 31]. Previous major ion exchange and aggregate effect, admixture of $\mathrm{Ca}^{2+}, \mathrm{Mg}^{2+}$ exchange of clay particles on the surface of $\mathrm{K}^{+}, \mathrm{Na}^{+}$, and soil particles adsorption of water film thickness are reduced, which reduces soil plasticity, swelling, and dry density, and moisture content is also reduced, larger soil aggregate is deepened, forming the close link between them and leading to soil structure change, and clay content decreases. In addition, long time carbonic acid reaction occurs between $\mathrm{CO}_{2}, \mathrm{Ca}(\mathrm{OH})_{2}$ and $\mathrm{Mg}(\mathrm{OH})_{2}$ in soil, and $\mathrm{CaCO}_{3}$ is generated, which results in soil cementation and soil reinforcement. In the late stage of the ion exchange reaction, the silica gel and aluminum gel in the expansive soil further are hardened with the admixture to produce $\mathrm{CaSiO}_{3}$ and calcium aluminate, thus forming a stable protective film with strong adhesion and a network structure, which improved the strength of the soil and acted as a water-repellent effect, making the water of the expansive soil stable $[32,33]$. The plasticity, dilatancy, and other properties of soil can be improved obviously by four kinds of action. Besides, when there are more admixtures, the clay content of expansive soil is artificially reduced, which also improves the properties of expansive soil.

\section{Conclusions}

Based on the different amounts of coal gangue, fly ash, and lime admixture, 9 sets of mixing ratio schemes are designed and developed through orthogonal experiments. Routine laboratory tests and SEM in the experiment and the sensitivity analysis of the tested mechanical performance indicators were carried out. The effect and microstructure of the improvement of expansive soil under the conditions of different admixture ratios of multiple admixtures were studied, and the optimal admixture ratio scheme was determined. Conclusions are obtained as follows.

(1) According to the orthogonal design, the physical and mechanical properties of the expansive soils were improved to different degrees by laboratory tests. 
(2) Based on range analysis and variance analysis, the main and secondary factors affecting the plasticity index of expansive soil are lime and fly ash. The sequences of influence on free expansion rate, shear strength, and unconfined compressive strength of expansive soil are lime, coal gangue, and fly ash. Through the comprehensive equilibrium method, the optimal mix ratio scheme of the improved expansive soil is $\mathrm{A}_{2} \mathrm{~B}_{3} \mathrm{C}_{3}$, which is $8 \%$ coal gangue, $11 \%$ fly ash, and $6 \%$ lime.

(3) Through the selection test, the optimal scheme of the technical specifications of the improved expansive soil is the best value, the free expansion rate was reduced by $35.7 \%$, the shear strength increases to $279.4 \mathrm{kPa}$, unconfined compressive strength increases to $1468.72 \mathrm{kPa}$, and the test results have been greatly improved, better than the lime improving expansive soil, and the reliability of the theory of mixture solution.

(4) Through SEM structure analysis, it can be concluded that the microstructure of plain expansive soil is mainly flat aggregate and granular particles, and the bulk aggregate is the main expansive soil particles after ash mixing. The soil structure is dense, the agglomeration of particles increases, and the soil has better integration performance. The improvement mechanism of expansive soil was analyzed, and it was found that when coal gangue powder, fly ash, and lime were added into expansive soil, physical and chemical reactions would mainly take place. Ion exchange, granulation, carbonation, and gelation were used to reduce the swelling and shrinking property of expansive soil and improve the strength of soil.

\section{Data Availability}

The data used to support the findings of this study are available from the corresponding author upon request.

\section{Conflicts of Interest}

The authors declare that they have no conflicts of interest.

\section{Acknowledgments}

This work was fully supported by these grants from the National Natural Science Foundation of China (Award nos. 51778227, 51308208, and 41372303), the Provincial Natural Science Foundation of Hunan (Award nos. 2015JJ3069 and 18C0311), the Youth Talent Plan Program of Hunan (Award no. 2016RS3032), and the Postgraduate Scientific Research Innovation Project of Hunan Province (Award no. CX20200992).

\section{References}

[1] H. Li, Comprehensive Utilization of Coal Gangue, Chemical Industry Press, Beijing, China, 2010.

[2] L. ting, C. Tang, and D. Xu, "Research progress on engineering geological characteristics of expansive soil," Journal of Engineering Geology, vol. 26, no. 1, pp. 112-128, 2018.

[3] Z. Yang, D. Hu, and Z. Wang, "Analysis on the evolution and disturbance law of expansion and shrinkage cracks in expansive soil," Journal of Agricultural Engineering, vol. 35, no. 17, pp. 169-177, 2019.

[4] X. Wang, Z. Yao, F. Dang, and Z. Dong, "Microstructural evolution test of fissure expansive soil," Journal of Agricultural Engineering, vol. 32, no. 3, pp. 92-100, 2016.

[5] G. Li, A. Li, J. Yuan, J. Wu, X. Cao, and S. Wu, "Cracking regularity and influencing factors of expansive soil on slope of river course in Jihuai River Project of Yanjiang River," Journal of Agricultural Engineering, vol. 34, no. 12, pp. 154-161, 2018.

[6] N. Liu, K. Liu, and L. Rong, "Research on coal gangue and its application in building materials," Concrete and Cement Products, vol. 10, no. 9, pp. 74-76, 2012.

[7] J. Wang and L. Wang, "Research on coal gangue clinker cement," Cement, vol. 3, no. 12, pp. 9-12, 2004.

[8] F. Meng, Study on the Shear Strength and CBR Variation Law of Coal Gangue Expansive Soil Subgrade, Inner Mongolia Agricultural University, Hohhot, China, 2012.

[9] T. Shen, S. Xing, S. Wang, M. Cheng, and W. Huang, "Screening of composite modifier for reducing the expansion rate of strong expansive soil and increasing the shear strength," Chinese Journal of Agricultural Engineering, vol. 33, no. 2, pp. 109-115, 2017.

[10] X. Yang and Y. Zhang, "Analysis on the shear strength mechanism of improved expansive soil with coal gangue powder," Coal Engineering, vol. 46, no. 9, pp. 123-125, 2014.

[11] Y. Zhang, X. Yin, and L. Tong, "Characteristics of coal gangue expansive soil and pore structure characterization under optimum mixing amount," Journal of Agricultural Engineering, vol. 34, no. 22, pp. 267-274, 2012.

[12] Y. Zhang, X. Kang, and L. Guo, "Research on engineering characteristics of improved expansive soil with lime coal gangue," Chinese Journal of Silicate, vol. 34, no. 9, pp. 2720-2724, 2015.

[13] M. W. Wang, K. Ge, and D. R. Zhu, "Experimental study of engineering behaviors on improved expansive soils in the Xinqiao Airport runway of Hefei," Advanced Materials Research, vol. 261-263, no. 261-263, pp. 1329-1335, 2011.

[14] Q. Qiu, "Study on properties of lime improved expansive soil under dry wet cycle," Subgrade Engineering, vol. 1, pp. 79-83, 2021.

[15] S. Dai, M. Song, and J. Huang, "Engineering properties of expansive soi," Journal of Wuhan University of Technology (Material Science Edition), vol. 20, no. 2, pp. 109-110, 2005.

[16] M. Abbaspour, S. S. Narani, E. Aflaki, F. M. Nejad, and S. M. M. M. Hosseini, "Strength and swelling properties of a waste tire textile fiber (WTTF)-reinforced expansive soil," Geosynthetics International, vol. 27, no. 5, p. 1, 2020.

[17] P. Indiramma, C. Sudharani, and S. Needhidasan, "Utilization of fly ash and lime to stabilize the expansive soil and to sustain pollution free environment - an experimental study," Materials Today: Proceedings, vol. 22, no. 3, pp. 694-700, 2020. 
[18] P. Gireesh Kumar and S. Harika, "Stabilization of expansive subgrade soil by using fly ash," Materials Today: Proceedings, vol. 22, no. 12, pp. 1-4, 2020.

[19] JTJ E40-2007, Highway Geotechnical Test Rules, People's Communications Press, Beijing, China, 2007.

[20] JTJ034-2000, Technical Specification for Highway Pavement Base Construction, People's Communications Press, Beijing, China, 2000.

[21] GBT 1596-2017, Fly Ash Used in Cement and Concrete, People's Communications Press, Beijing, China, 2017.

[22] S. Shan, Experimental Study on Cement-Lime Improved Loess and its Engineering Application, Chang'an University, Xi'an, China, 2017.

[23] Y. Li and C. Hu, Experimental Design and Data Processing, Chemical Industry Press, Beijing, China, 2008.

[24] Q. Liu, W. Xiang, and D. Cui, "Research on the mechanism of improving expansive soil with ionic soil stabilizer," Chinese Journal of Geotechnical Engineering, vol. 33, no. 4, pp. 648654, 2011.

[25] L. S. Chafusheng and Y. Du, "Improvement of expansive soil with lime and fly ash," Journal of Southeast University (Natural Science Edition), vol. 37, no. 2, pp. 339-344, 2007.

[26] F. G. Bell, "Lime stabilization of clay minerals and soils," Engineering Geology, vol. 42, no. 1/2, pp. 223-237, 1996.

[27] Y. Li, W. He, and H. Wang, "Calculation of critical value of F test method," Nonferrous Metals (Mineral Processing), vol. 4, pp. 39-41, 1992.

[28] J. K. Mitchell, Fundamentals of Soil Behavior, Wiley\&Sons, New York, NY, USA, 2nd edition, 1993.

[29] L. Tan, M. Zhang, W. Shao, and H. Lili, "Microstructural characteristics and engineering properties of disastrous expansive soils," Journal of Geotechnical Engineering, vol. 2, pp. 48-57, 1994.

[30] B.-H. Ma, Z.-Y. Hu, Z. Li et al., "Finite difference method for the one-dimensional non-linear consolidation of soft ground under uniform load," Frontiers in Earth Science, vol. 8, no. 8, pp. 1-9, 2020.

[31] B. Ma, Z. Li, K. Cai et al., "An improved nonlinear settlement calculation method for soft clay considering structural characteristics," Geofluids, vol. 2021, no. 1, 7 pages, Article ID 8837889, 2021.

[32] B. Ma, Z. Li, K. Cai et al., "Pile-soil stress ratio and settlement of composite foundation bidirectionally reinforced by piles and geosynthetics under embankment load," Advances in Civil Engineering, vol. 2021, no. 1, 10 pages, Article ID 5575878, 2021.

[33] B. Ma, Z. Hu, Z. Li et al., "A three-section-settlement calculation method for composite foundation reinforced by geogrid-encased stone columns," Advances in Civil Engineering, vol. 2021, no. 2, 10 pages, Article ID 5576713, 2021. 